Revue d'histoire de l'Amérique française

REVUE D.HISTOIRE DE L'AMÉRIQUE FRANÇAISE

\title{
Chronique de la Fondation Lionel Groulx
}

\section{Juliette Lalonde-Rémillard}

Volume 17, numéro 3, décembre 1963

URI : https://id.erudit.org/iderudit/302309ar

DOI : https://doi.org/10.7202/302309ar

Aller au sommaire du numéro

Éditeur(s)

Institut d'histoire de l'Amérique française

ISSN

0035-2357 (imprimé)

1492-1383 (numérique)

Découvrir la revue

Citer ce document

Lalonde-Rémillard, J. (1963). Chronique de la Fondation Lionel Groulx. Revue

d'histoire de l'Amérique française, 17(3), 467-467.

https://doi.org/10.7202/302309ar d'utilisation que vous pouvez consulter en ligne.

https://apropos.erudit.org/fr/usagers/politique-dutilisation/ 


\section{CHRONIQUE DE LA FONDATION LIONEL GROULX}

Deux des membres de la "Fondation" ont reçu récemment des honneurs que nous ne pouvons passer sous silence. Le Docteur Jacques Genest, vice-président, s'est vu décerner le prix Gairdner $(\$ 5,000)$, en reconnaissance d'une contribution importante à la recherche en médecine. Plus récemment, le Collège des médecins et chirurgiens du Québec instituait le prix "Jacques Genest" en hommage au directeur du département des recherches cliniques à l'Hôtel-Dieu de Montréal. Le Collège motivait son geste en ces termes:

Le Collège veut ainsi stimuler l'intérêt des futurs médecins dans le domaine de la recherche clinique et attirer l'attention des autorités sur l'urgente nécessité de favoriser par tous les moyens possibles l'établissement et le maintien d'un laboratoire de recherches médicales.

Ce prix annuel de $\$ 600$ sera décerné au gagnant d'un concours organisé parmi les étudiants en quatrième année de médecine dans les universités de Montréal, Laval et McGill. Le sujet du concours aura une relation avec le domaine de la recherche en médecine ou en chirurgie.

Un autre membre de la Fondation, M. Roger Charbonneau, directeur de l'École des Hautes études commerciales de Montréal, reçoit, pour sa part, un honneur nullement à dédaigner: il s'est vu proclamer "l'homme du mois" (en janvier 1963) par la revue Commerce, revue de la Chambre de commerce du district de Montréal.

Nos archives: Elles s'enrichissent constamment. Tout dernièrement M. Dominique Beaudin nous apportait tout un dossier de la "Ligue de la défense du Canada": ligue fondée, comme l'on sait, en 1943, pour combattre un projet du gouvernement d'Ottawa, projet de conscription pour la guerre d'Outre-mer. A ce propos, nous pouvons annoncer une bonne nouvelle à ceux de nos amis qui hésitent parfois à nous confier des papiers fort précieux. Ils n'auront plus à craindre les ravages du feu ou de l'eau. La "Fondation" fera construire d'ici peu une voûte où pourront trouver un abri de pleine sécurité tous les documents que nous avons déjà amassés et ceux-là dont l'on voudra bien nous faire don.

JULIETTE LALONDE-RÉMILLARD, sec. 